\title{
PEDAGOGICAL POSSIBILITIES OF USING THE SUBJECT "FOREIGN LANGUAGE" IN THE FORMATION OF A MULTILINGUAL PERSONALITY
}

\author{
Nuraiym Tulyuvbekova1, Gulbanu Aubakirova² \\ ${ }^{1}$ E.A.Buketov Karaganda University, Karaganda, Kazakhstan \\ ${ }^{2}$ E.A.Buketov Karaganda University, Karaganda, Kazakhstan
}

ORCID ID: 0000-0002-2542-055X

\begin{abstract}
Knowledge of several languages gives a real opportunity to take a worthy position in society, both socially and professionally. Multilingual education in the Republic of Kazakhstan is one of the most important strategies and key directions for the development of the state. The author examines the essence of multilingual education, the reasons for its relevance in the Republic of Kazakhstan, the functioning of languages from the point of view of the development of a modern linguistic personality. Taking into account the advantages of linguistic education in the multilingual educational environment of Kazakhstan and the principles of the formation of a linguistic personality, the author compared different views on this issue.
\end{abstract}

\section{INTRODUCTION}

Currently, the purpose of teaching a foreign language is not to develop a set of language skills and abilities specific to individual knowledge of the culture of the country in which it is taught, but to develop an active and productive linguistic personality in a global multicultural language [Petrova, Uteubayeva, Kokhanover, 2020]. The task of a modern teacher is to create a complex of motivation and self-learning skills. Without the help of the teacher, there is no domination over the student. Proper teacher-student cooperation presupposes the teacher's ability and knowledge to measure and guide the independence provided to the student, which ultimately leads to goal setting and cognitive automation [Linde \& Petrova, 2018]. The content of multicultural education should reflect the ideas of humanism, take into account the peculiarities of peoples' cultures, show what they have in common with each other in the world, and contribute to understanding the interdependence of people in the modern situation.

Among the areas of work on the formation of a multilingual personality can be divided into:

- formation of multicultural competences of primary schoolchildren.

- multicultural education as a class teacher

- interactive training

- Comparative study of Russian and English grammar.

- the formation of interpersonal relationships in adolescents

In the process of cognitive activity, the ideas about the image of the world are very similar. However, the formation of this image is influenced not only by communication and knowledge, but also by language, which is a means of creating a unique reality, a culture in which a person lives. The role of language not only in the transmission of messages, but also in the internal organization of the transmitted, the linguistic picture of the world reflects various images of the human world and reflects the general image of the world. 
The entry into force of the state educational standards of the second generation has presented new requirements for teachers to achieve the goals of the educational process that meet the needs of modern society.

The main task of training is to enable students to independently set and implement educational goals, evaluate their own achievements.

In the conditions of competition of new educational standards, the methodology of teaching a foreign language has undergone corresponding changes taking into account the requirements of education and the development of a cultural, creative and developed personality.

The second generation standards define the following objectives of teaching English:

1. The development of communicative competence in a foreign language as a whole as its components: verbal, linguistic, socio-cultural, intercultural, compensatory, educational and cognitive abilities.

2. Personal development of students.

3. Formation and development of universal educational activities.

Expected Learning Outcomes:

1. The purpose of the results.

2. According to individual results:

- formation of language motivation; formation of communicative competence and common cultural and ethnic identity;

- understand the possibilities of self-realization through a foreign language and try to improve the general culture of speech;

- strive to better understand the culture of your people and be ready to help represent representatives of other countries;

Tolerance to other cultures and the desire to defend national and universal values, their civic status.

3. The results of the meta-system include:

- development of communication skills and scientific and educational activities;

- be able to clearly identify areas of knowledge and ignorance;

- identify tasks that need to be solved in order to achieve goals, plan actions, predict results, analyze effectiveness, draw conclusions, make adjustments, define new goals and objectives based on the results of work, be able to;

- implementation of self-control, self-control, self-assessment in the process of communicative activity in English.

With the results of the second generation SESE educational process:

- socialization;

- expansion of general language thinking, development of cognitive, emotional and volitional spheres;

- mastering the rules of linguistic behavior and linguistic concepts necessary for mastering familiar speech in a foreign language, expanding linguistic horizons;

- Establish friendly relations and tolerance towards native speakers of other languages based on children's knowledge of folklore about the life of their peers in other countries [Karaulov Y.N., 1987].

These requirements must be implemented in the classroom and in extracurricular activities. Therefore, it was necessary to look at the text from the point of view of the requirements of the new generation standard. Then it will be clear what needs to be changed in the activities of the teacher and student in preparation for the current lesson.

Today, the school is not a source of information, as it is taught to read; the teacher is no longer a leader of knowledge, but a person who teaches creative activities aimed at independent acquisition and acquisition of new knowledge. The nature of the behavior of the teacher and the student is changing. The student ceases to be a passive participant in the educational process and, together with the teacher, participates in determining the goals and objectives of each lesson, sets his own action 
plan, chooses tools and methods to achieve his goals, actively participates in the evaluation of his activities and results.

The formation of a universal educational activity is the basis of the students' ability to further self-development and self-education. To form a universal learning activity in the context of teaching English, the student must find answers to the following questions: "Why am I learning a foreign language?", "Why am I doing this or that exercise in the classroom (reading, writing, listening)? "," Why am I studying at home? Repeat? "," What did I learn in the class and what else do I need to do?".

The language is considered in the following aspects:

- the main means by which we absorb culture;

- as a factor of culture, because it is an integral part of it, inherited from our ancestors;

- the most important of all cultural phenomena.

Being an integral part of culture and its instrument, it nakedly presents the peculiarities of the national mentality, reveals the mechanisms of the zone of consciousness. Also, the relationship between language and culture is considered as the relationship of the part and the whole.Since each mother tongue is at the same time the native language of a culture, linguistic signs can serve as cultural signs and, thus, serve as a means of expressing basic views on the speech of the speaker.

Language is a means of obtaining information about the material and spiritual culture of society, which is rooted in the cultural nature of the individual. The level of development of the language, its contribution to the life of the country, the world of people who speak it, determines the scope of the language and the scope of its functions.

From an early age, a child learns the first elements of a multicultural language space. He enters into language activity, acquires skills and norms of norm-evaluating behavior, draws multicultural ideas from fairy tales, gets an idea of the functions of the language space in role-playing games, and his ideas gradually slow down, build up at the beginning. Childhood, but a kind of multicultural life. At this stage it becomes possible to work and develop the language activity of children.

Currently, the concept of educational technologies has firmly entered the educational lexicon. The terminology explains the concept as follows: "Technology is a set of methods used in any profession, skill..."[Khaleeva I.I., 1995]. Teaching methods for creating, applying and conditioning the entire learning and knowledge process.

Therefore, one of the key technologies is individually oriented technologies that put the child's personality at the center of the entire preschool education system, provide a comfortable, conflictfree and safe environment for his development and realization of his natural potential.

Within the framework of human-oriented technologies, many others are independent - these are technologies of cooperation. They work in partnership between a teacher and a child. Teachers and children work together to develop goals and content and assessment in a collaborative creative environment. Problem-oriented learning is an organization that today, under the guidance of a teacher, seeks to create active independent activities for children to solve problem situations and resolve them, which leads to the creative development of knowledge, skills and abilities. Working with children as equal partners, individuals, groups of individuals, although limited, can provide practical mastery of multicultural language activities.

One of the phases of any technology is the phase of inspiration or interest. There is an opportunity to work with children. There are times when a child is "reborn" as an actor. We are talking about methods that "simulate" the situation of real voice communication, that is, gaming technologies. The purpose of this method:

1. to expand the field of didactic thinking, the formation of knowledge in practice;

2. Education for independence, cooperation, teamwork, communication;

3. Developmental - development of attention, memory, speech, thinking, comparison, comparison skills;

4. Adaptation to social and environmental conditions, communication. Computer technologies for teaching with digital images, videos, presentations, music tracks [Shayakhmetova A. A., 2014].

According to the new state standard, the main purpose of primary education is to determine the personality of the student and the development of learning activities. Preschool children are 
sensitive to learning activities, their mental activity is focused on repetition, internal perception, imitation, learning activities and statements. In addition, preschoolers have abstract thinking that they need to see. The computer acts as a tool, as adding some visual elements to the learning process helps to overcome difficulties. When children see color pictures, diagrams, dynamic pictures on the computer screen, they better understand and master new complex material.

Computerization of the process includes a new way of learning that gives pleasure to children and saves teachers time.

The reasons for the success of teaching children multicultural language activities:

- to influence the personality of the child as a whole, to stimulate his speech, cognitive and creative abilities;

- creating an atmosphere in which the child feels comfortable and free; developing his desire to engage in multicultural language activities;

- activate the preschooler, create his main active personality, actively interact with other participants;

- create conditions in which the teacher is not the central figure.

All this creates favorable conditions for the productive organization of children's activities through the use of innovitive educational technologies.

When teaching foreign languages, especially speech, it is necessary to take into account the psychophysiological peculiarities of thinking of children of younger preschool age and use methods and techniques that contribute to the development of speech, logical and verbal thinking in children due to the activation of imaginative thinking.

Methods and techniques of speech development. The method of speech development is defined as a method of actions of teachers and children, which provides training in speech skills and abilities.

There are three groups of methods:

1. Visualization: showing toys, pictures, photos, description, description of pictures and toys, talking about toys and pictures, excursions, inspection of premises, inspection of natural objects, this knowledge, consolidation of vocabulary, development of the general function of the word, communication skills.

2. Vocabulary: explanation, question-answer. Phonetic exercises, nursery rhymes, memorization, use of oral folklore, reading and narration of works of art, synthesis of conversations - all oral methods require visual methods.

3. Listening, logarithm: games-dramatization, staging, plastic sketches, theatrical performances [Skorikova T.P., 2013].

Rapid integration of Kazakhstan into the world community: an innovative and industrial economy, public consciousness, coordination of the educational space and the introduction of international standards will radically change human consciousness and behavior. The socio-historical transformation of society and the orientation towards the social form of consciousness and the values of human culture in general confirmed the priority of three languages in the Republic of Kazakhstan: Kazakh-Russian - English. Along with the state Kazakh language and the language of interethnic communication - Russian, a foreign language is also an important means of communication.

\section{CONCLUSIONS}

The main trends determening the development of multilingualism in Kazakhstan have been outlined. According to the Law of the Republic of Kazakhstan "On Education" of 2007, all educateonal institutions, regardless of the form of ownership, must ensure that students study Kazakh as the state language, as well as Russian and one of the foreign languages in accordance with mandatory state requirements. educational standard. New times and new circumstances require a radical transformation, a reassessment of values and ideals, a revision of the goals and objectives of teaching methods and techniques. Learning foreign languages in Kazakhstan means learning this language as an independent true means of communication at the level of the native language of this language. 
Learning a foreign language develops the necessary communication skills as a member of society, a team member, a family member. This includes the ability to listen, communicate and support the interlocutor.

Multilingual teaching of foreign languages at an early stage contributes to the qualitative study of many languages in the future, which allows you to continue studying abroad in order to make a choice in the global educational space.

Thus, the main educational task of an English teacher is to create favorable conditions for successful learning activities in the classroom. But for this, the teacher must know exactly what to teach and how to teach.

The novelty of modern education in Kazakhstan requires an individual beginning on the part of a teacher who is able to teach him traditional education, equipping students with knowledge, skills and abilities or developing a modern understanding of these knowledge, skills and abilities, formation of their values and meanings.

\section{REFERENCES:}

Karaulov Y.N. (1987) “ Russian language and linguistic personality”. 261 p.

Khaleeva I.I. (1995) Secondary linguistic personality as a recipient of a foreign text. Language is a system. Language - text. Language is an ability.160 p.

Linde, I., Petrova, M. (2018) The challenges of formalization and modeling of Higher Education Institutions in the 21st century. CBU International conference proceedings 2018: Innovations in Science and Education, 21.-23.03.2018, pp.303-308, https://doi.org/10.12955/cbup.v6.1173

Petrova, M., Uteubayeva, E., Kokhanover, T. (2020). Didactic approach to the process of communicative competence formation. Bulletin of the Karaganda university/ Pedagogy series. ISSN 2518-7937 (Print). ISSN 2663-516X (Online). № 4(100)/2020. http://dx.doi.org/10.31489/2020Ped4/79-84

Shayakhmetova A. A. (2014) "Formation of a multilingual educational environment in the system of higher education"

Skorikova T.P. (2013) Teaching the theory and practice of intercultural communication (using a virtual educational environment) / Bulletin of RUDN. Ser. "Russian and foreign languages and methods of teaching them." - 2013 / - No. 2. - P. 136-143. 4. Skorikova T.P. The working program of the academic discipline "Theory". - 2013 / - No. 2. - P. 136-143. 